\title{
Infrared Spectroscopy for Studying Foods and Biodegradable Packaging
}

\author{
Oksana Shulga, Anastasiya Chorna, Larisa Arsenieva, and Sergii Shulga
}

National University of Food Technologies, Kiev 01033, Ukraine

\begin{abstract}
The results of study of foods and biodegradable film structure with the use of infrared spectroscopy (IR spectra) are presented. For the first time detailed decodings of IR spectra of some foods and biodegradable film packaging materials are shown. Interpretation of the spectra of basic biopolymers of foods and biodegradable films is given. It is corroborated with the help of IR spectra that the chemical reactions in biopolymers when heated to $130{ }^{\circ} \mathrm{C}$ do not occur, which makes it possible to use biologically valuable raw materials. Furthermore, the expediency of use of IR spectroscopy for studying changes in foods and films produced on biopolymer base is established. IR spectroscopy is a fast method that allows you to monitor changes that occur with the raw materials in the technological process. Previously, IR spectroscopy was used to identify the compounds in chemical synthesis. This study shows that IR spectra can be used for study of foods and biodegradable film structure.
\end{abstract}

Key words: IR spectra, biodegradable films, foods, biopolymers, starch.

\section{Introduction}

For a long time infrared spectroscopy (IR spectroscopy) has been used to study foods. Thus, some references give IR spectra atlases of some foods, carboxylic acids and natural polymers, but they do not provide interpretation of the mentioned spectra so there is no complete understanding of the spectra of each product. Some authors completely decode the IR spectrum of cellulose and give important data about the IR spectra of starch. At the same time, the authors note that the full interpretation of the spectrum of cellulose still causes some difficulty, since cellulose has a complex structure of a macromolecular monomeric unit.

Unlike cellulose there are few published studies of starch. Furthermore, all IR spectra are given in the literature without proper decoding and interpretation $[1,2]$.

\section{Materials and Methods}

The IR spectroscopy is used to determine the depth

Corresponding author: Sergii Shulga, $\mathrm{PhD}$, professor NUFT, research field: heterocyclic compounds. of possible changes in thermal processing conditions (e.g., extrusion) of main and additional raw materials. All kinds of raw materials used to produce potato sticks before and after extrusion, and also extrudates from mixtures of raw materials in different combinations and ratios are studied. For accurate decoding the spectra of glucose, sucrose, pectin, leucine, dipeptide glycine asparagine, casein are also obtained. A total of 37 spectra are obtained on the Nicolet Nexus 475 FT-IR Spectrometer, France. Spectra of the films and raw films (14 spectra) are obtained on the Bruker Tensor 37 FT-IR.

The spectra of input materials and biodegradable film as corn starch, modified high amylose starch, modified starch, special dextrin refined from tapioca starch, gelatin, glycerol and the IR spectra of developed biodegradable films were studied.

\section{Results and Discussion}

The analysis shows that spectrum 1 and spectrum 2 are completely identical even in the non-characteristic range of the spectrum $\left(400-1,000 \mathrm{~cm}^{-1}\right)$, that is known [3] to be very important for the IR spectra, as numerous $\mathrm{C}-\mathrm{C}, \mathrm{C}-\mathrm{N}, \mathrm{N}-\mathrm{O}$ stretching vibrations and 
deformation vibrations do not occur in this range, which can not be practically interpreted.

This vibration range of the molecule carbon skeleton dramatically reacts to minor changes in the structure of molecule. Non-characteristic vibrations make up the main part of the spectrum and form a unique set of stripes for each substance. There are no compounds with identical spectra except enantiomers (optical antipodes). Some references show that this factor is used for determination of the identity of the samples under research. In other words, the IR spectrum of the substance is its important characteristic, which has greater value than melting or boiling temperature.

In our case, there is the number of vibrations in the non-characteristic range in the spectrum 1, in particular at $929.78 \mathrm{~cm}^{-1}, 846.0 \mathrm{~cm}^{-1}, 759.51 \mathrm{~cm}^{-1}$, $704.0 \mathrm{~cm}^{-1}, 573.78 \mathrm{~cm}^{-1}$, and the corresponding vibrations at $931.12 \mathrm{~cm}^{-1}, 848.00 \mathrm{~cm}^{-1}, 706.00 \mathrm{~cm}^{-1}$, $753.55 \mathrm{~cm}^{-1}, 577.00 \mathrm{~cm}^{-1}$ in the spectrum 2. These values can be considered as equal under the condition of experiment. Consequently, specified ranges are starch fingerprints.

Some authors cite data for spectral separation of starch and cellulose having (or missing) certain bands in the IR spectrum. Thus, starch is characterized by bands at $920 \mathrm{~cm}^{-1}, 850 \mathrm{~cm}^{-1}, 760 \mathrm{~cm}^{-1}$ and $700 \mathrm{~cm}^{-1}$, but these stripes are absent or very weak in spectrum of cellulose. At the same time, absorption bands, which are typical for cellulose, as $1,430 \mathrm{~cm}^{-1}, 1,370$ $\mathrm{cm}^{-1}, 1,280 \mathrm{~cm}^{-1}, 670 \mathrm{~cm}^{-1}$, are absent in the starch spectrum.

Similar comparative characteristic of vibrations can be also observed in characteristic range: at 3,421.44 $\mathrm{cm}^{-1}, 2,922.14 \mathrm{~cm}^{-1}, 1,636.96 \mathrm{~cm}^{-1}, 1,419.26 \mathrm{~cm}^{-1}$, $1,158.00 \mathrm{~cm}^{-1}, 1,082.31 \mathrm{~cm}^{-1}, 1023,71 \mathrm{~cm}^{-1}$ in the spectrum 1 (Fig. 1a), and at $3,422.02 \mathrm{~cm}^{-1}, 2,925.59$ $\mathrm{cm}^{-1}, 1,655.96 \mathrm{~cm}^{-1}, 1,420.49 \mathrm{~cm}^{-1}, 1,156.29 \mathrm{~cm}^{-1}$, $1,081.47 \mathrm{~cm}^{-1}, 1,022.41 \mathrm{~cm}^{-1}$ in the spectrum 2 (Fig. 1b). So, values are almost the same.

Based on the statements above, we can consider that spectrum 1 and spectrum 2 are identical, that is why all absorption bands are made for the spectrum 1 . The broad intense band at $3,421.44 \mathrm{~cm}^{-1}$ corresponds to the valence $v \mathrm{OH}$ vibrations. It is known, that the position and the nature of bands depend on the degree of envolvement of hydroxyl group in hydrogen bonds. Hydrogen bonds change the power constant of the $\mathrm{O}-\mathrm{H}$ bond, reducing the frequency of vibrations. Hydroxyl group, which takes part in intermolecular hydrogen bond, is characterized by broad, intense absorption at 3,200-3,600 $\mathrm{cm}^{-1}$ maximum. Broad absorption band exists at $3,385.14 \mathrm{~cm}^{-1}$.

It is known, that the formation of intermolecular hydrogen bonds is almost impossible in dilute solutions of carbon tetrachloride with $=<0.005 \mathrm{~mol} / \mathrm{L}$ concentration. Hydroxyl group of such solutions in IR spectrum is a narrow intense band at $3,610-3,620 \mathrm{~cm}^{-1}$ range. It is also known, that the part of dry cellulose is less than $1 \%$ in the share of free $\mathrm{OH}$ groups. Almost all the hydroxyl groups are bound in the crystalline ranges. The band 2,929.69 $\mathrm{cm}^{-1}$ under valance vibrations $v \mathrm{C}-\mathrm{H}$ exists in the residua of starch glucopyranose ring.

The absorption band $1,654.36 \mathrm{~cm}^{-1}$ belongs to the bending vibrations of adsorbed bound water. This absorption band is clearly shown in the form of medium intensity band at $1,633-1,655 \mathrm{~cm}^{-1}$ in all the spectra of potato sticks and additional primary products before and after extrusion, as well as glucose, sucrose (Fig. 2), pectin, casein (Fig. 3).

Other absorption bands of the spectrum 1 were interpreted using literature sources. The full interpretation of bands is introduced in Table 1.

Thus, the analysis of the infrared spectra of dried mashed potato before and after extrusion shows complete identity of the spectra, which means that chemical transformations that change the chemical structure of starch do not occur during extrusion. Some authors also state that the IR spectra of potato sticks derived from mixtures of biopolymers are identical to the spectra of the mechanical mixture of 


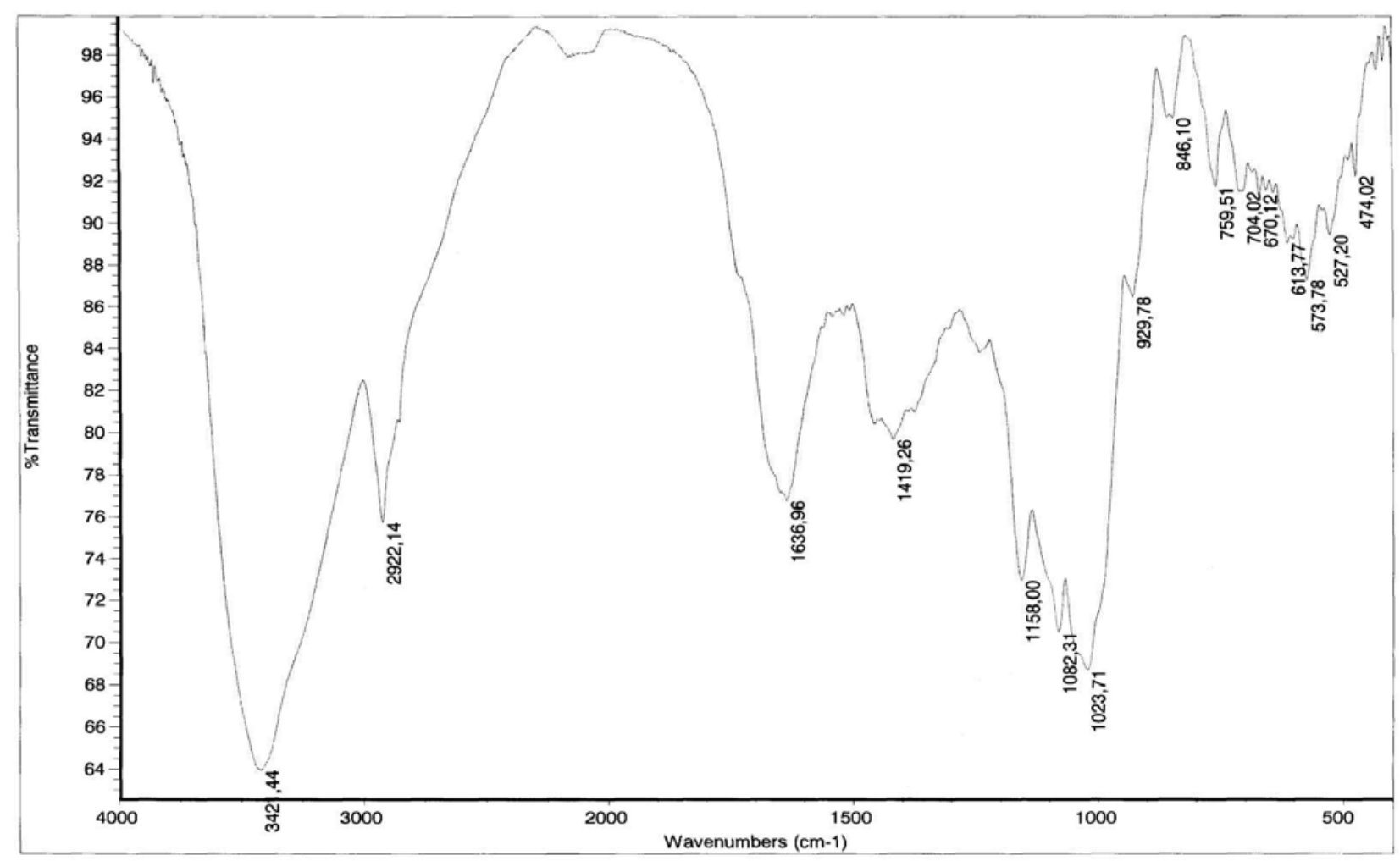

(a) The spectrum 1

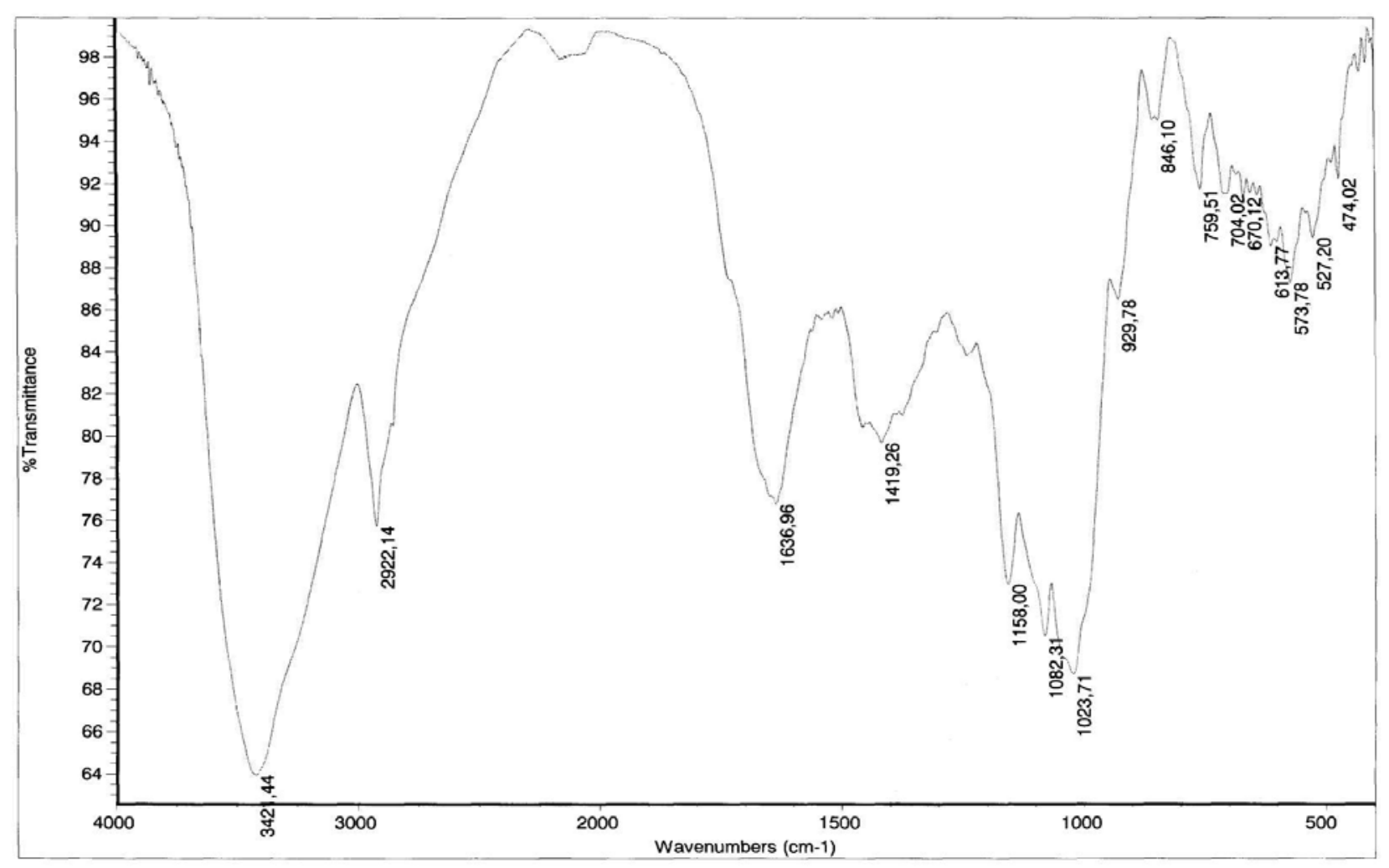

(b) The spectrum 2

Fig. 1 The IR-spectrum of dried mashed potato before extrusion (the spectrum 1) and after extrusion (the spectrum 2). Two spectral lines belong to the same product, but in different concentration. 


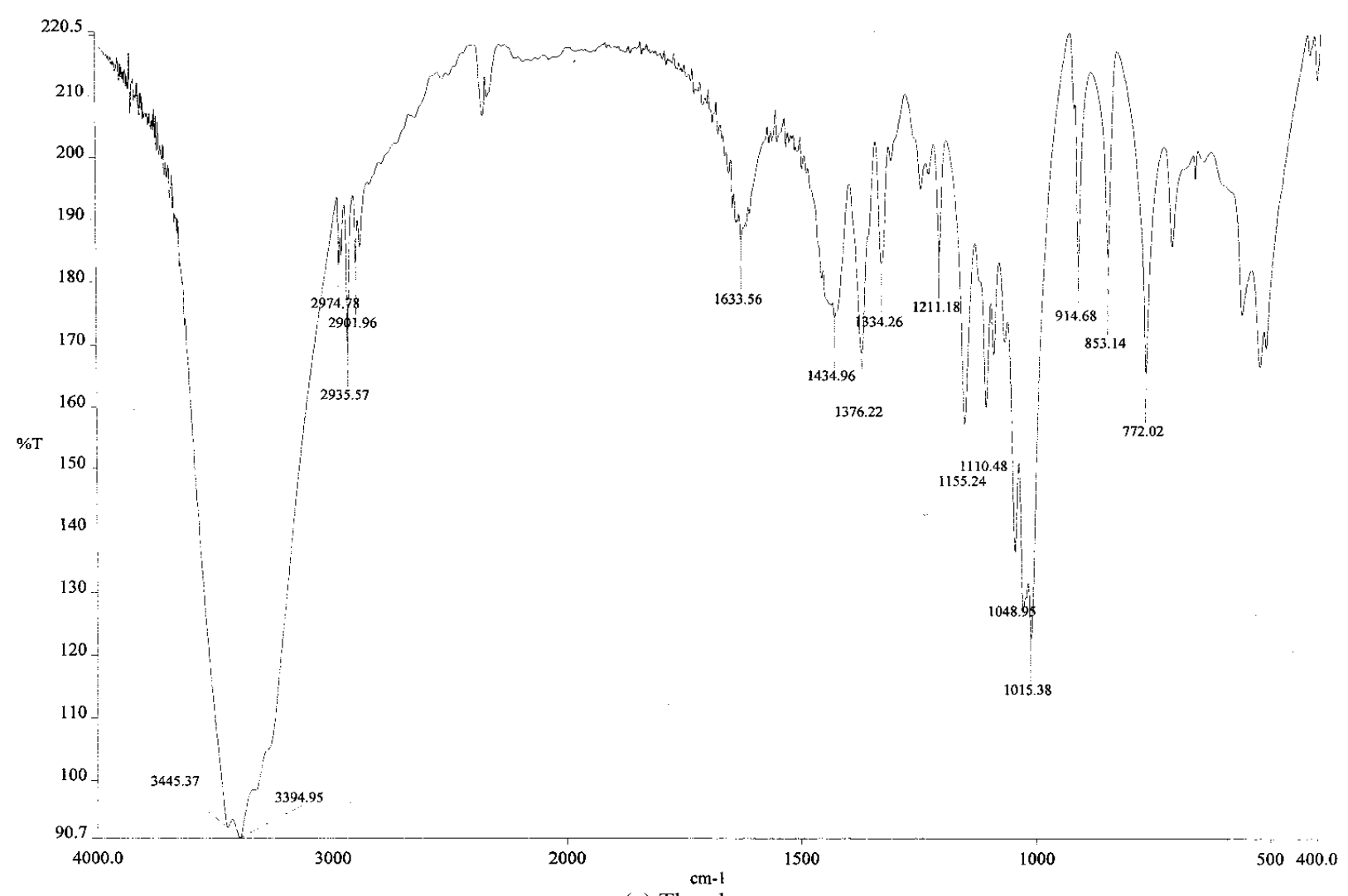

(a) The glucose

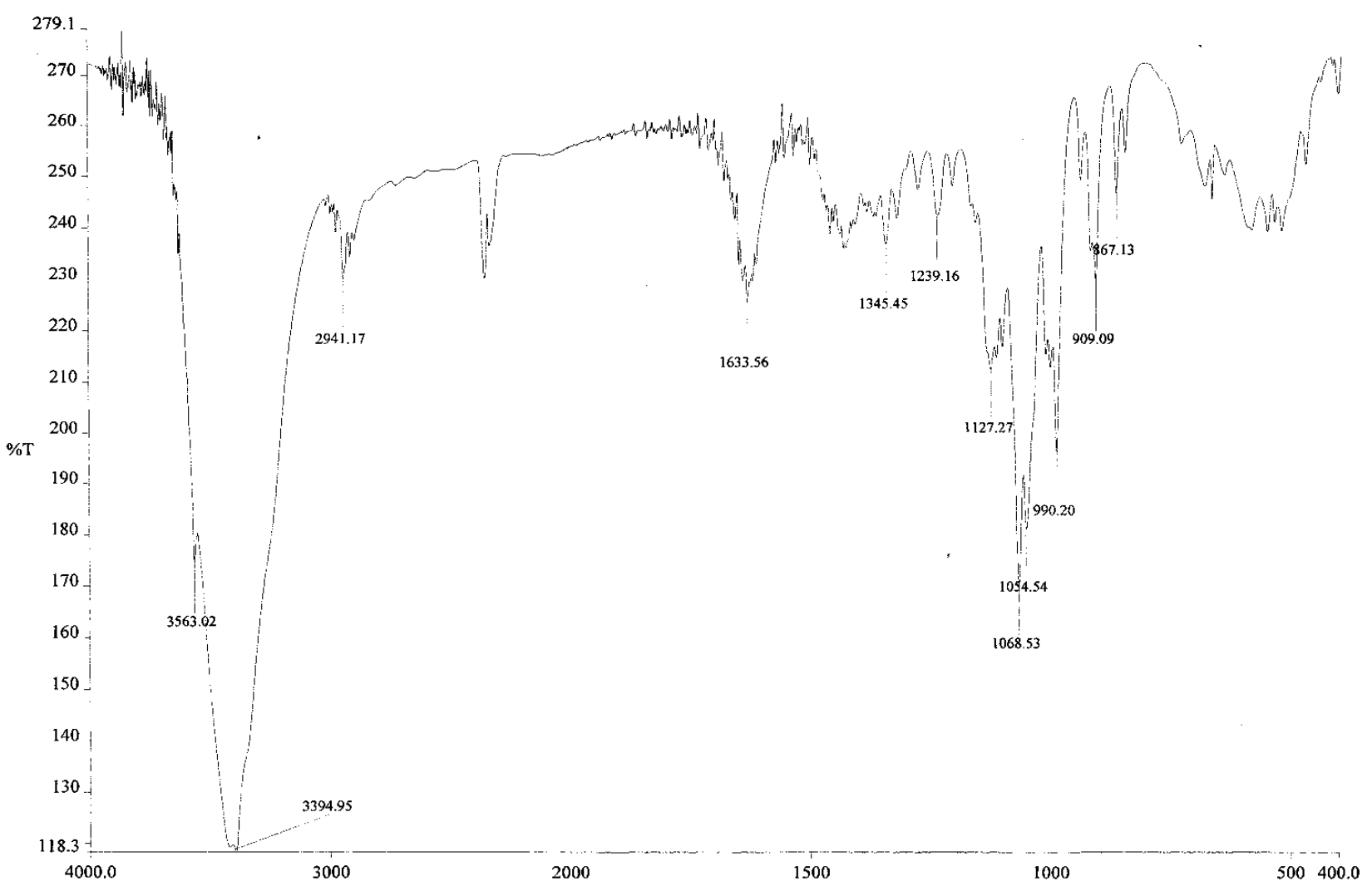

Fig. 2 The IR spectra of the glucose and the sucrose.

(b) The sucrose 


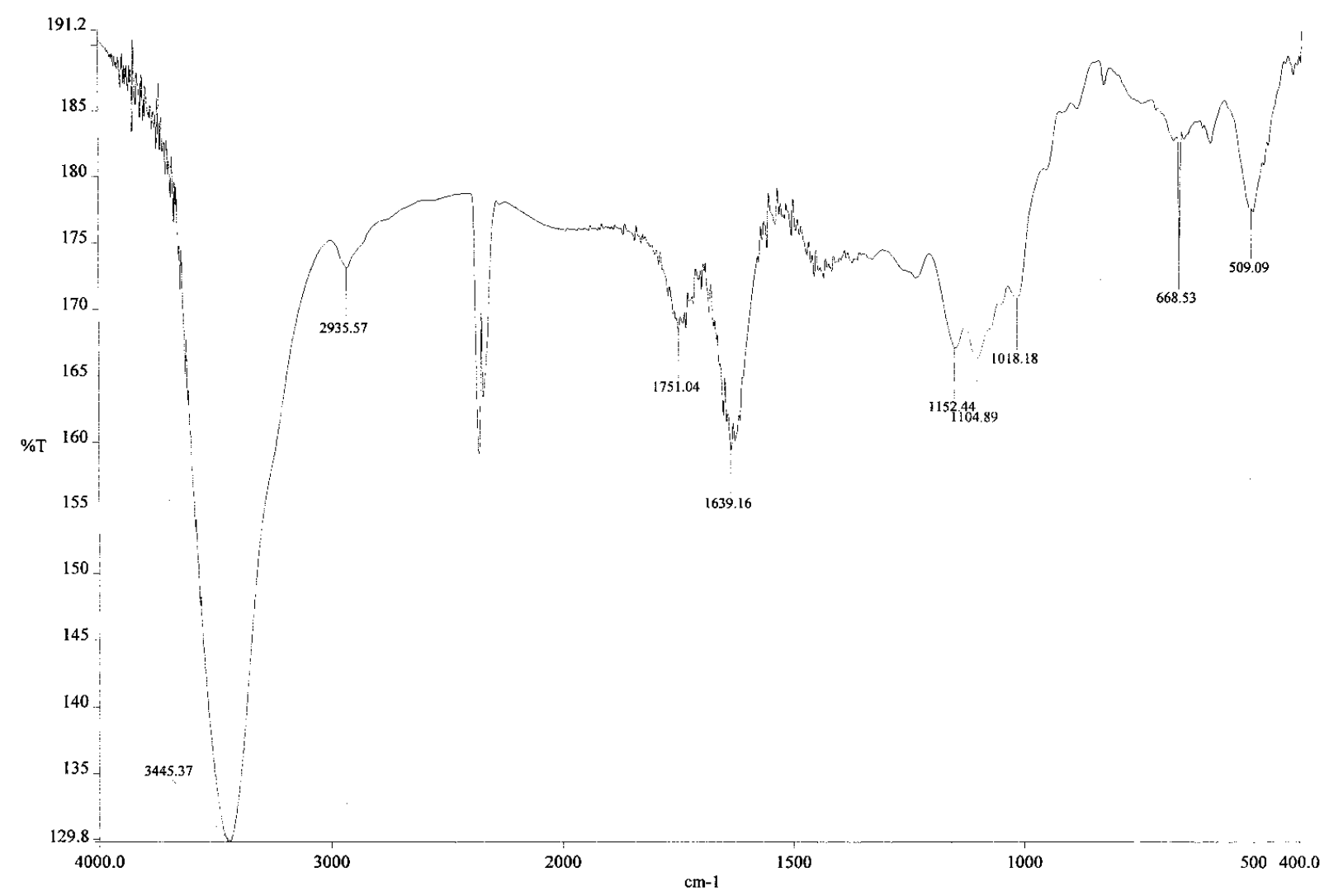

(a) The pectin

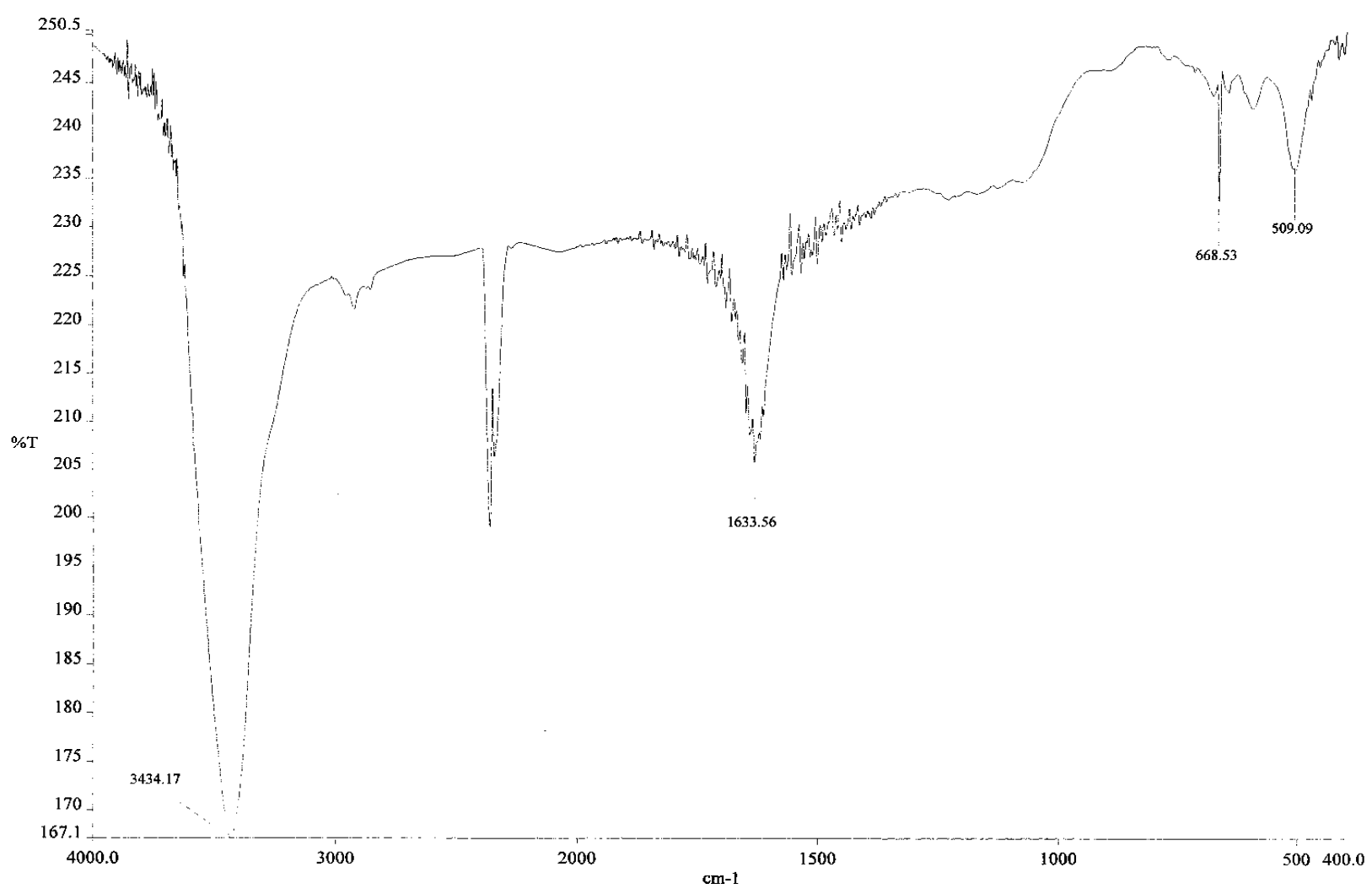

(b) The casein

Fig. 3 The IR spectra of the pectin and the casein. 
Table 1 Absorption bands in the midrange of the IR spectrum of starch.

\begin{tabular}{|c|c|c|}
\hline The wave number, $\mathrm{cm}^{-1}$ & Band intensity & Vibrations \\
\hline $1,419.26$ & average & $\delta\left(\mathrm{CH}_{2}\right)+\delta(\mathrm{CH})$ \\
\hline $1,158.00$ & average & $\delta(\mathrm{OH})+\delta\left(\mathrm{CH}_{2}\right)$ \\
\hline $1,082.31$ & average & $v_{\mathrm{a}}(\mathrm{C}-\mathrm{O}-\mathrm{C})$ bridge \\
\hline $\begin{array}{l}10,023.71 \\
929.78\end{array}$ & $\begin{array}{l}\text { average } \\
\text { traces }\end{array}$ & \}$v(\mathrm{C}-\mathrm{C}), v(\mathrm{C}-\mathrm{OH}), \delta(\mathrm{CH}), \delta(\mathrm{OH})$ \\
\hline $846.10^{*}$ & traces & $\mathrm{v}_{\mathrm{s}}(\mathrm{C}-\mathrm{O}-\mathrm{C})$ bridge \\
\hline 759.51 & traces & ring vibrations \\
\hline \begin{tabular}{|l|}
704.02 \\
670.12 \\
613.77 \\
573.78 \\
527.20 \\
474.02
\end{tabular} & $\begin{array}{l}\text { traces } \\
\text { traces } \\
\text { traces } \\
\text { traces } \\
\text { traces } \\
\text { traces }\end{array}$ & $\begin{array}{l}\text { All these absorption bands have not a clear atribution. It is } \\
\text { believed that, the skeletal vibrations of } \mathrm{C}-\mathrm{C} \text { bonds or } \\
\text { absorption of pyranose ring occur in this range }\end{array}$ \\
\hline
\end{tabular}

Note. Anomeric bound of glucopyranose rings may be recognized by the absorption in the range of $800-900 \mathrm{~cm}^{-1} . \alpha$-glucoside bond absorbs at $844 \pm 8 \mathrm{~cm}^{-1}, \beta$-configuration - at $891 \pm 7 \mathrm{~cm}^{-1}$. In the spectrum 1 this absorption band lies at $846.10 \mathrm{~cm}^{-1}$, which corresponds to $\alpha$-glucoside bond of the typical structure of starch. In the cellulose spectrum this band lies at $895 \mathrm{~cm}^{-1}$. In the sucrose spectrum (Fig. 3) this band is at $867 \mathrm{~cm}^{-1}$, indicating the presence of $\beta$-glycosidic bond between the $\alpha$-D-glucopyranose and $\beta$-D-fructofuranose.

powders which were heated on the base of particular components. This means that, according to IR spectroscopy, that new types of bonds, which indicate the chemical interactions of proteins of soya bean and starch hydrolysis products, are not formed in potato sticks. Moreover, in the spectrum of the dry mixture of heated mashed potato and peas where the content of protein compounds is $10.3 \%$, there is no change in comparison with the spectrum 2 . Thus, the interaction of the carbonyl group of hydrolyzed starch and nitrogen-containing compounds (Maillard reaction) is remote. The analysis of the spectrum of skimmed milk powder and the spectrum of extrudate with skimmed milk powder brings to the similar conclusion.

So, taking into account other indicators of research: the degree of swelling, water absorption capacity, the amount of water-soluble substances, and others, it is established that during heating of starch with limited amount of water $(15 \%-18 \%)$, starch gelatinizes and partially hydrolyzes to various dextrins. During hydrolysis carbonyl (aldehyde) groups are usually formed, but in the IR spectra the typical band of carbonyl group is absent.

It is known [4], that the stretching vibrations of the carbonyl group, irrespective of vibrations in the functional group to which they belong, show the high intensity peak at $1,650-1,850 \mathrm{~cm}^{-1}$, where the other bands are practically absent. Vibrations $v \mathrm{C}=\mathrm{O}$ are the most typical ones and allow to prove presence or absence of substance of the carbonyl group.

As it has been already noted, during the hydrolysis of starch in the process of extrusion in places of discontinuity of glucosidic bonds aldehyde groups are certainly formed, but immediately, due to the tautomerism phenomenon, these final glucose residues from carbonyl form transform into glucopyranose form.

Furthermore, the authors believe that the carbonyl group in the cyclic form of carbohydrates is hydrated and can be found only in solution in very small amounts, which complicates the melanoidins formation. It can be assumed that this reaction occurs forming oximin or azomethine in such small amounts that only IR spectroscopy can determine. In addition, we do not exclude the possibility that the amount of generated azomethine affects in the certain way the color of the potato sticks, but in our opinion, caramelization of various carbohydrates with formed polymer compounds is the main factor, which affects the color of extruded products. 
The temperature is a decisive factor of this process. Thus, the melting point of glucose is $83{ }^{\circ} \mathrm{C}$, fructose is 102-104 ${ }^{\circ} \mathrm{C}$, maltose is $102-103{ }^{\circ} \mathrm{C}$, and as noted above, the extrusion process occurs at $125-135{ }^{\circ} \mathrm{C}$. Under such circumstances, the process of caramelisation of carbohydrates with the formation of polymeric compounds certainly occurs, and these compounds stain potato sticks.

IR spectra analysis of additional raw materials showed that there is a $1,738.27 \mathrm{~cm}^{-1}$ band corresponding to $\mathrm{vC}=\mathrm{O}$ esters in the spectrum of carrot powder (Fig. 4). The infrared spectrum of the mixture extrudate in which $20 \%$ carrot powder is a component, this band is absent. During extrusion the ether probably evaporates with steam with or without pre-hydrolysis.

The beet powder IR spectrum contains the similar band at $1,737.50 \mathrm{~cm}^{-1}$. The spectrum of the dry extrudate mixture of mashed potatoes $(90 \%)$ and beet powder $(10 \%)$, does not contain this band. The reasons of this band absence are explained for the IR spectra of carrot powder.

The IR spectrum of apple powder has an absorption band at $1,735.21 \mathrm{~cm}^{-1}$, which corresponds to $\mathrm{vS}=\mathrm{O}$ esters. The spectrum of the dry extrudate mixture of mashed potatoes (80\%), and apple powder (20\%), does not contain this absorption band. The reasons for its disappearance are similar to the above ones.

There is wide absorption band of average intensity in the spectrum of skimmed milk at $3,366.17 \mathrm{~cm}^{-1}$. It is known that $\mathrm{vNH}$ stretching vibrations are shown at $3,100-3,500 \mathrm{~cm}^{-1}$. The intensity of the bands is significantly less than the intensity of vON bands (spectrum glitsilasparagina) located almost in the same range. $\mathrm{vNH}$ frequency depends on the degree of involvement of the group in hydrogen bonds, but it is less than for $v O N \quad 3,300-3,500 \mathrm{~cm}^{-1}$ (free), $3,100-3,300 \mathrm{~cm}^{-1}$ (bound). Typically the band, which corresponds to the primary amino group, is double, and in this case it is single, that is typical for secondary amino groups (at 3,310-3,350 $\mathrm{cm}^{-1}$ ).
Deformation vibrations $\delta \mathrm{NH}$ give untypical band of moderate intensity at $1,580-1,625 \mathrm{~cm}^{-1}$ for the primary amino group and 1,500-1,600 $\mathrm{cm}^{-1}$ - for the secondary one. There is a band of vibrations in the spectrum of skimmed milk (Fig. 4) at 1,543.44 $\mathrm{cm}^{-1}$, which corresponds to deformation vibrations of the secondary amino group which are absent in the spectra of carrot, beet, and apple powder.

The band of deformation vibrations with a low-intensity is observed in the secondary amino group at 1,542.94-1,560.55 $\mathrm{cm}^{-1}$ range in the spectrum of the extrudate with $10 \%$ of skimmed milk.

The spectrum of millet before extrusion is similar to the spectra of mashed potato and other raw materials, but there is a low absorption band in the spectrum of millet at $2,855.25 \mathrm{~cm}^{-1}$, which corresponds to the stretching vibrations of the groups $\left(\mathrm{CH}_{2}\right)$. There is also a band of vibrations with low intensity at $1,743.89 \mathrm{~cm}^{-1}$, which corresponds to $\mathrm{vS}=\mathrm{O}$ ester group. The presence of these bands is explained by the fact that millet contains fat. In turn, there are higher fatty acids in fat containing the groups $\left(-\mathrm{CH}_{2}\right)$ bound with glycerol by an ester group $(-\mathrm{O}-\mathrm{C}=\mathrm{O})$.

The bands have a residual character in the spectra of mixtures of extrudates, which contain millet, that can be explained by decreased amount of millet to $45 \%$ and the prevalence of mashed potato (55\%), as well as additional raw materials in formulation.

The spectrum of corn grits can be interpreted similarly to the spectrum of millet, as there is a fat in the corn grits, which is the cause of the absorption bands at the range of 2,854.90 and $1,745.15 \mathrm{~cm}^{-1}$. These bands also occur in the spectra of extruded potato, which contains corn grits, and also have a small intensity, as well as in the spectra of millet. The total fat content is increased in the spectra of extrudates of mixtures, where there are both millet and corn grits, and therefore the intensity of the corresponding band increases a little.

In the spectra of potato extrudates the band of vibrations occurs at $1,562-1,510 \mathrm{~cm}^{-1}$, which corresponds 


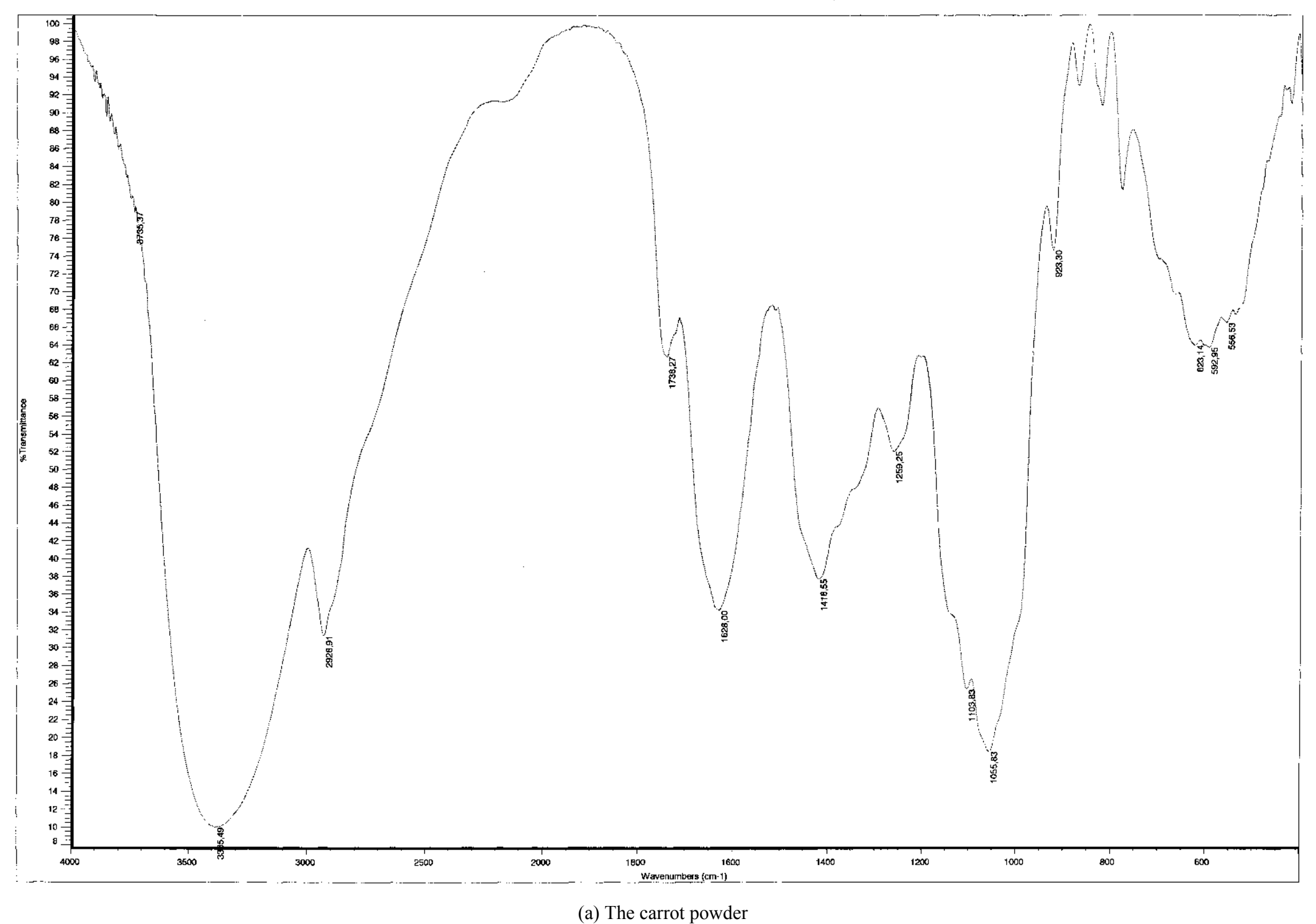




$$
\text { Lu }
$$


to $\delta \mathrm{NH}$ and is expected because pea contains $22.8 \%$ of protein compounds. Furthermore, a strong band at $3,405.91 \mathrm{~cm}^{-1}$ which corresponds to $v \mathrm{ON}$ and $\mathrm{vNH}$, occurs at low frequencies $\left(3,421.44 \mathrm{~cm}^{-1}\right.$ for mashed potato) and is wider, indicating the effect of $v \mathrm{NH}$.

The spectra of potato sticks with barley have a typical general shape, specific for all extruded potato products. Unlike the spectrum of mashed potato, barley spectrum contains a clear absorption band of medium intensity at $1,543.44 \mathrm{~cm}^{-1}$, which corresponds to $\delta \mathrm{NH}$ vibrations and confirms the presence of nitrogen compounds in the barley grits.

The spectra of potato products, which contain rice, are completely identical with the spectrum of dry mashed potato along the width of the spectrum.

Comparing the general shape of the spectra of main raw materials (dry mashed potato) and additional raw materials, we can conclude that they are similar. However, a logical question arises: how can IR spectra of different in nature and origin raw materials (dry mashed potato, vegetable and fruit powders, skimmed milk powder, cereals) be similar? To answer this question it is necessary to consider the IR spectra of glucose, sucrose and pectin (Figs. 3 and 4). These spectra are similar in general shape with the spectra of extruded potato products. In our opinion, this can be explained by the fact that the main "function" determining the type and nature of the IR spectra of extruded potato products, as well as additional raw materials is a glucopyranose ring. It is a part of disaccharides and polysaccharides (starch, cellulose), which all types of raw materials used in research contain. Moreover, taking into account the spectrum of pectins, we can assert that the pyranose ring (regardless of whether it is glucose or galactopyranose) plays the main role in the IR spectra of starchy foods, as the presence of the furanose ring of sucrose significantly changes the uncommon range of absorption. It is clear that nitrogenous substances and fats in products insert to IR spectra additional bands of absorption.
Biodegradable packaging films, used as potato sticks packaging, were the other object of the study. Biodegradable films are considered to be modern packaging [3, 5]. Biodegradable films obtained by boiling of biopolymers mixture (starch (various types) $1.5 \%, 3.1 \%$ gelatin with glycerol $[6,7]$ in an aqueous medium) were examined by IR spectra. It was necessary to determine whether the chemical transformations occur in the components of the films when heated.

The spectra of input materials and biodegradable film as corn starch, modified high amylose starch, modified starch, special dextrin refined from tapioca starch, gelatin, glycerol and the IR spectra of developed biodegradable films were studied. Formulations of developed and investigated films are shown in Table 2.

All obtained IR spectra (Figs. 5 and 6) have the same general shape and differ only in the range of fingerprints, intensity and frequency of the same vibrations, depending on the degree of hydrogen bonds in the output product.

All spectra have a strong narrow band of vibrations at a range of 997.14-1,020.29 $\mathrm{cm}^{-1}$, corresponding to vibrations $v(\mathrm{C}-\mathrm{O}), v(\mathrm{C}-\mathrm{C}), \gamma(\mathrm{C}-\mathrm{H})$, which collide.

The IR spectra of the products containing starch have a non-characteristic absorption range (range of fingerprints the same as the IR spectrum of potato starch in Fig. 1: $929.78 \mathrm{~cm}^{-1} ; 846.10 \mathrm{~cm}^{-1} ; 759.51 \mathrm{~cm}^{-1}$; $704.02 \mathrm{~cm}^{-1}$ ), $925,78 \mathrm{~cm}^{-1}$ for corn starch; $858.78 \mathrm{~cm}^{-1}$; $759.91 \mathrm{~cm}^{-1} ; 709.98 \mathrm{~cm}^{-1}$, and a film № 6-921,92 $\mathrm{cm}^{-1} ; 850.56 \mathrm{~cm}^{-1} ; 754.12 \mathrm{~cm}^{-1} ; 653.83 \mathrm{~cm}^{-1}$. IR spectra have a wide band of vibrations with different intensity at 3,284.59-3,273.01 $\mathrm{cm}^{-1}$, which corresponds to the stretching vibrations of the $-\mathrm{OH}$ or -NH groups. Thus, various starches have an intense wide band of stretching vibrations of $\mathrm{OH}$ groups, namely: modified high amylose starch at 3,400.31 $\mathrm{cm}^{-1}$, modified starch at $3,433.10 \mathrm{~cm}^{-1}$, special dextrin refined from tapioca starch at $3,388.74 \mathrm{~cm}^{-1}$, corn starch at $3,409.95 \mathrm{~cm}^{-1}$, glycerol at $3,363.66 \mathrm{~cm}^{-1}$, and 
Table 2 Composition of investigated biodegradable films.

\begin{tabular}{|c|c|c|}
\hline Sample number & Composition & Content, $\%$ \\
\hline \multirow{4}{*}{1} & Modified high amylose starch & 2 \\
\hline & Gelatin & 2 \\
\hline & Glycerol & 1 \\
\hline & Water & 95 \\
\hline \multirow{4}{*}{2} & Modified high amylose starch & 3 \\
\hline & Gelatin & 3 \\
\hline & Glycerol & 1.5 \\
\hline & Water & 92.5 \\
\hline \multirow{4}{*}{3} & Modified starch & 5 \\
\hline & Gelatin & 3.5 \\
\hline & Glycerol & 2.5 \\
\hline & Water & 89 \\
\hline \multirow{4}{*}{4} & Modified high amylose starch & 2 \\
\hline & Gelatin & 2 \\
\hline & Glycerol & 1.5 \\
\hline & Water & 94.5 \\
\hline \multirow{4}{*}{5} & Modified starch & 1 \\
\hline & Gelatin & 1 \\
\hline & Glycerol & 1 \\
\hline & Water & 97 \\
\hline \multirow{3}{*}{6} & Corn starch & 5 \\
\hline & Glycerol & 2 \\
\hline & Water & 93 \\
\hline \multirow{3}{*}{7} & Special dextrin refined from tapioca starch & 2 \\
\hline & Glycerol & 1.8 \\
\hline & Water & 96.2 \\
\hline
\end{tabular}

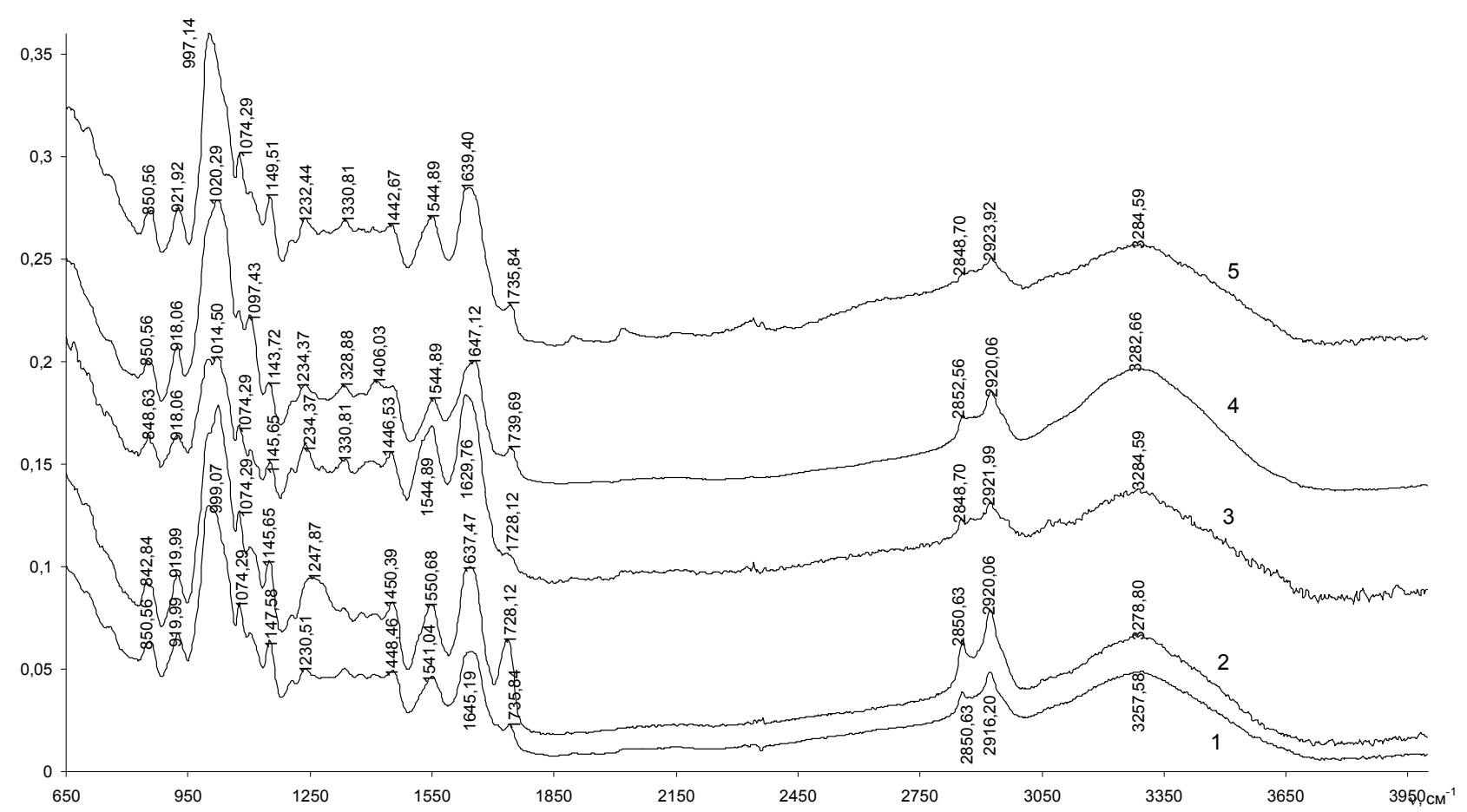

Fig. 5 The IR spectra of developed biodegradable films (samples № 1-5). 

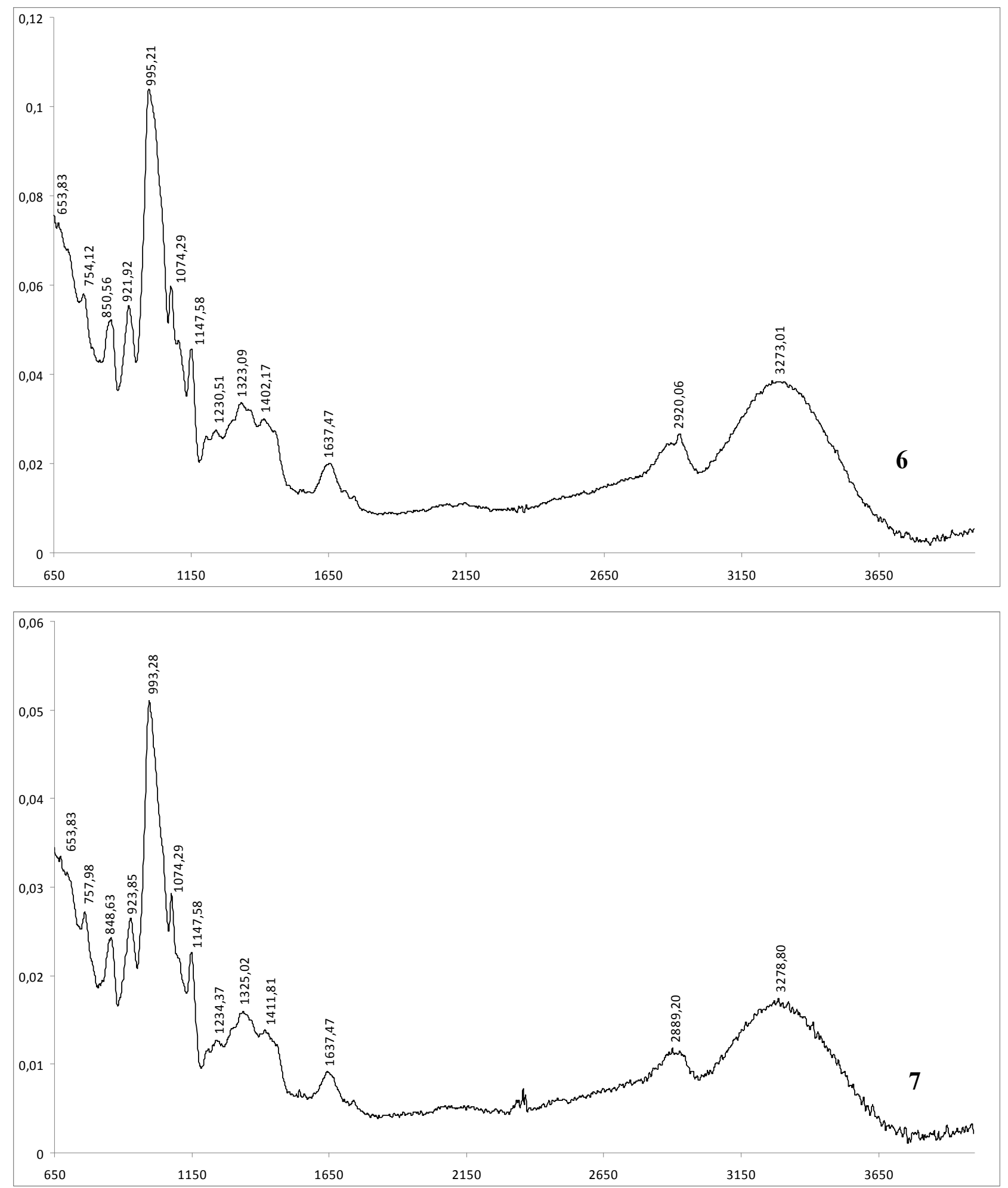

Fig. 6 The IR spectra of developed biodegradable films (samples № 6, № 7).

the corresponding films (Fig. 6) which have a wide intense $\mathrm{OH}$ band at $3,273.01 \mathrm{~cm}^{-1}$ and at $3,278.80 \mathrm{~cm}^{-1}$. This indicates that the hydroxyl group is strongly bound via hydrogen bonds of starch with glycerin. It should be emphasized that the hydroxyl groups in glycerin are more associated than in starch $(3,367.66$ 
$\mathrm{cm}^{-1}$ in glycerol, $3,409.95 \mathrm{~cm}^{-1}$ in starch).

In the IR spectra of films containing gelatin, bands of vibrations occur at $1,544.89 \mathrm{~cm}^{-1}$ and $1,763.84 \mathrm{~cm}^{-1}$ (Fig. 5). The first band refers to the deformation vibrations $(\delta \mathrm{NH})$, and the second refers to the vibrations of $\mathrm{C}=\mathrm{O}$ group, which is a part of amino acids.

\section{Conclusions}

Starch foods can be identified by IR spectra, as they have non-characteristic absorption range (range of fingerprints), which is located at $920 \mathrm{~cm}^{-1}, 850 \mathrm{~cm}^{-1}$, $760 \mathrm{~cm}^{-1}$ and $700 \mathrm{~cm}^{-1}$.

Using IR spectroscopy we ascertained that during heating (particularly during extrusion at $125-135{ }^{\circ} \mathrm{C}$, the boiling point of the solution is more than 110-120 ${ }^{\circ} \mathrm{C}$ when producing films), substantial chemical changes, that could affect the chemical changes in raw material structure do not occur such as changes in types of bonds between glucopyranose ring, changes in the ring shaper, formation of new bonds or functional groups. Thus, IR spectroscopy can be considered as a reliable method of establishing the changes of foods and biodegradable films.

\section{References}

[1] Bradfild, I. 1997. "Pushing forward the Boundaries of On-line Analysis." Food Manuf. 7: 31-2, 34.

[2] Burakov, V. S., Stepanenko, A. B., Zhuravleva, V. I., Kiris, V. V., Litvyak, V. V., and Tarasenko, N. V. 2012. "Upakovka." The Packaging, Vol. 16-21.

[3] Korotka V. O., and Zatserkovna R. S. 2013. "Kvaliologiya Knigi." Kvalilogiya of the Book, 69-72.

[4] Braun, D., Floyd, A., and Seynzberi, M. 1992. Spektroskopiya Organicheskikh Veshchestv [Spectroscopy of organic substances]. Moscow: Mir Publ., 300.

[5] Embuscado, M. E., and Huber, K. C. 2009. Editors Edible Films and Coatings for Food Applications. Springer Science+Business Media, 335-47.

[6] Zlotnikov I. I., and Khilo P. A. 2014. "Vestnik Gomelskiy Gosudarstvenny Tekhnicheskiy Universitet." Journal of the Gomel State Technical 1: $52-8$.

[7] Tsomko M. I., Sirenko H. O., and Mazepa I. V. 2012. "Visnyk Prykarpatskoho natsionalnoho universytetu imeni Vasylia Stefanyka." Journal of Carpathian National University of Vasiliy Stefanik. Chemistry Series XIV: 109-28. 